\title{
Medical complications of achondroplasia: a multicentre patient review
}

\author{
A G W Hunter, A Bankier, J G Rogers, D Sillence, C I Scott Jr
}

Department of Genetics, Children's Hospital of Eastern Ontario, Department of Pediatrics,

University of Ottawa, Ottawa, Ontario K1H 8L1, Canada A G W Hunter

Department of Genetics, Royal Children's Hospital, Parkville 3052,

Melbourne, Australia A Bankier

J G Rogers

Department of Paediatrics and Child Health, University of Sydney, The New Children's Hospital, Parramatta, NSW 2124, Australia

D Sillence

\section{Alfred I duPont} Hospital for Children, Wilmington, DE, USA C I Scott Jr

Correspondence to: Dr Hunter, Department of Genetics, Children's Hospital of Eastern Ontario, 401 Smyth Road, Ottawa, Ontario K1H 8L1, Canada.

Received 19 December 1997 Revised version accepted for publication 2 March 1998

\begin{abstract}
Achondroplasia is the most prevalent chondrodysplasia and numerous authors have documented the varied social and medical complications that may compromise a full and productive life. Complications include cervicomedullary compression, spinal stenosis, restrictive and obstructive lung disease, otitis media, and tibial bowing, among others. These known complications have led to recommendations for the anticipatory management of such patients. There are relatively few data on the actual rates and timing of these problems. This paper reports data on the rates and age of occurrence of several of these complications based on a review of recorded chart information of 193 patients ascertained from several well established genetic centres with a known interest in the chondrodysplasias. The length of follow up varied and the rates of occurrence at specific age intervals were used to estimate the cumulative percentage affected for each complication. The report includes information on otitis media, ventilation tubes, hearing loss, tonsillectomy, speech problems, tibial bowing and osteotomy, ventricular shunting, apnoea, cervicomedullary decompression, and neurological signs attributable to spinal stenosis. $(\mathcal{M}$ Med Genet 1998;35:705-712)
\end{abstract}

Keywords: achondroplasia; otitis media; tibial bowing; neurological signs

Achondroplasia has an estimated incidence of $1 / 26000^{1}$ and is the most prevalent chondrodysplasia. Although achondroplasia is generally considered to be associated with normal intelligence and, in most cases, normal longevity ${ }^{2}$ and thus to be compatible with a full and productive life, many authors have documented the varied medical and social complications that may conspire to compromise those prospects. The most serious is narrowness of the cervical canal or foramen magnum or both, which may cause cervicomedullary compression and consequent risk of death, ${ }^{2}{ }^{3}$ central apnoea, ${ }^{4}$ and neurological signs and symptoms including paraparesis. ${ }^{5}$ Other of the more common complications include respiratory signs as a result of either a small chest ${ }^{4}{ }^{6}$ or upper airway obstruction, ${ }^{4}$ gross motor delay associated with macrocephaly, hypotonia, and joint laxity, frequent otitis media which may be accompanied by hearing loss and delayed speech, ${ }^{7}$ bowing of the legs which may require tibial osteotomies, ${ }^{8}$ hydrocephalus, ${ }^{9}$ and generally later onset neurological complaints because of spinal stenosis. ${ }^{8}{ }^{10}$ Obesity may also occur $^{11}$ and has the potential to exacerbate both medical problems and the difficulties of psychosocial adaptation. ${ }^{12} 13$

Recognition that there are many potential complications for the patient with achondroplasia has led to efforts towards a multidisciplinary approach ${ }^{14}$ and anticipatory management, ${ }^{15}$ culminating in the position statement of the Committee on Genetics of the American Academy of Pediatrics (AAP). ${ }^{16}$ Despite recognition of these varied problems, there are relatively few data as to their age dependent rates of occurrence. This paper reports a chart review of prospectively recorded data from 193 patients with achondroplasia, often supplemented by interview, which attempts to add to information about the age and incidence of a number of these complications and medical interventions.

\section{Methods}

The conduct of this study and details of patient ascertainment have been described previously. ${ }^{6}$ The study was approved by the Research Ethics Review Committee of The Children's Hospital of Eastern Ontario. Most of the data presented in this study were abstracted from records in departments of genetics and from hospital charts, and in about $40 \%$ of cases was supplemented by direct interview (table 1). The greatest number of patients were from Wilmington, DE, and while few of those patients were directly interviewed, it was the practice of that clinic to see the children every six months to the age of 6 years and yearly

Table 1 Source of patients for this study

\begin{tabular}{lll}
\hline Source & $\begin{array}{l}\text { Total } \\
\text { patients }\end{array}$ & $\begin{array}{l}\text { No interviewed } \\
\text { at study }\end{array}$ \\
\hline Wilmington, DE & 108 & 7 \\
Sydney, NSW & 47 & 36 \\
Melbourne, VIC & 23 & 19 \\
Manchester, England & 12 & 12 \\
Cardiff, Wales/Ottawa, ON & 3 & 3 \\
Total & 193 & 77 \\
\hline
\end{tabular}




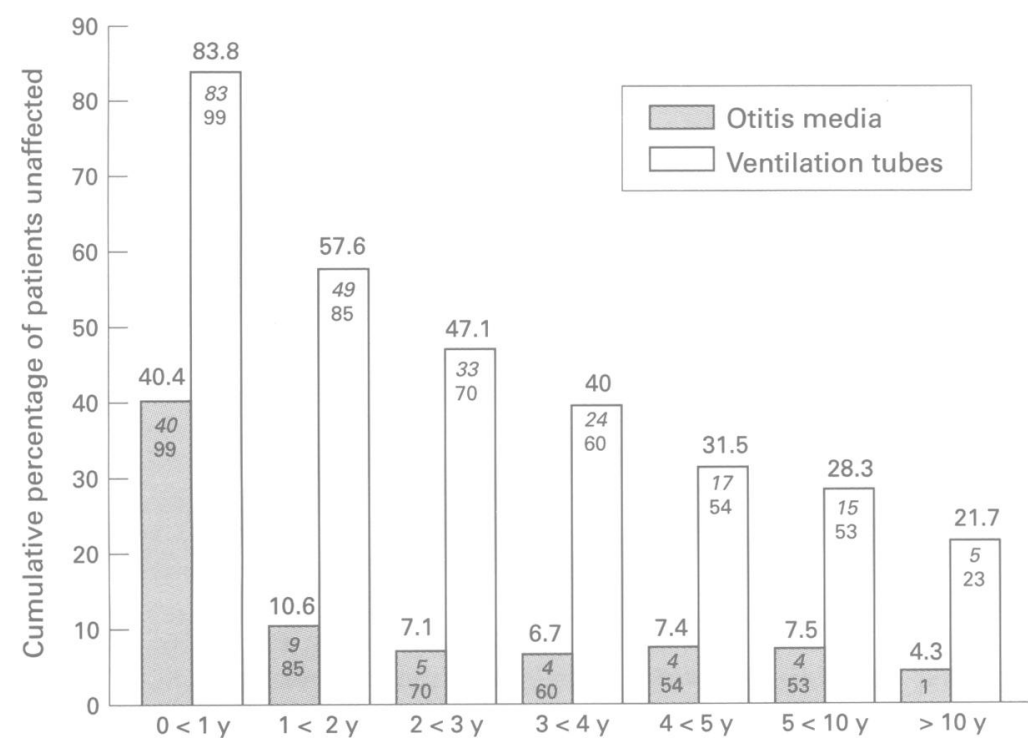

Figure 1 Disease free rates for otitis media and ventilation tubes over time for patients with prospective data. Numbers within columns are the actual numbers affected over the numbers followed in that age category.

Table 2 Patients with retrospectively obtained histories of middle ear disease (OM)

\begin{tabular}{|c|c|c|c|c|c|c|c|c|c|c|}
\hline \multirow[b]{2}{*}{ Ages (y) } & \multirow{2}{*}{$\begin{array}{l}\text { No of } \\
\text { cases }\end{array}$} & \multicolumn{3}{|c|}{ No of OM reported } & \multicolumn{6}{|c|}{ No of operations for tube placement } \\
\hline & & None & Several & Chronic & 0 & 1 & 2 & 3 & $\geqslant 4$ & $? N o$ \\
\hline $0-5$ & 9 & 0 & 5 & 4 & 0 & 4 & 1 & 3 & 0 & 3 \\
\hline$>5-10$ & 7 & 0 & 2 & 5 & 2 & 1 & 1 & 2 & 1 & 0 \\
\hline $10-20$ & 22 & 3 & 4 & 15 & 5 & 4 & 3 & 2 & 8 & 0 \\
\hline$>20$ & 36 & 11 & 9 & $13^{\star}$ & 24 & 3 & 4 & $\overline{1}$ & 3 & 1 \\
\hline
\end{tabular}

$\star$ Plus two cases of serous OM.

thereafter. A standard set of medical history questions and a physical examination were carried out at each visit. While the approach at the other clinics was somewhat less systematic, regular follow up visits were the norm and many of these patients were interviewed at the time of this study. Patients seen at special clinics, for example at Little People of America Inc meetings, were excluded so as to avoid ascertainment bias for medical problems. This study is partly cross sectional and includes patients from the first year of life to those in their late $50 \mathrm{~s}$, but it also encompasses significant longitudinal data on individual patients followed prospectively for a number of years.
Data were coded and entered in Statistical Package for the Social Sciences (SPSS/PC+) for data manipulation and descriptive analysis.

Results (figs 1 to 10, tables 2 and 3)

All patients on whom data were available who had an affected parent were diagnosed at, or occasionally before, birth. For the 134 patients with no parent with achondroplasia, the age at diagnosis was markedly skewed towards birth with 79 diagnosed at birth and $94 \%$ by 1 year of age. The mean age at diagnosis was 0.306 years and the oldest ages at diagnosis were at 7 and 8 years in patients who were born in 1965 and 1958, respectively. There was a significant correlation between the age at diagnosis and the age of the patient $(r=0.27, p=0.001)$, which suggests that a diagnosis is more likely to be made at or around birth today than it was previously.

The mean paternal age at birth of patients who had no family history $(34.85, \mathrm{n}=134)$ was older, but not statistically so, than patients who had an affected parent (31.66, $\mathrm{n}=22)$ $(0.05<\mathrm{p}<0.10)$.

Fig 1 shows the percentage of patients with achondroplasia who were followed prospectively and remained free from OM and ventilation tubes (VT) at various age intervals. Retrospective data (table 2) on OM are unlikely to be as reliable, especially as one gets further from childhood with its maximum rates of infection. However, they confirm the high childhood attack rate while at the same time $14 \%$ of patients aged $>10$ to 20 years claim not to have suffered from $\mathrm{OM}$.

Table 3 provides further data for the same age groups concerning the frequency and chronicity of the middle ear problems in the patients who were followed prospectively.

The columns in figs $2-10$ contain the actual reported rates of the specific complication for that age cohort. However, for most complications the major interest for the patient, family, and physician is how often and at what age does it occur. In other words, what is the "cumulative attack rate". Presentation of the data in that way is compromised by the fact that the complication may occur at a variable time after birth, whereas the number of patients on whom

Table 3 Rates of otitis media and ventilation tube placement at different ages for patients with prospectively obtained data

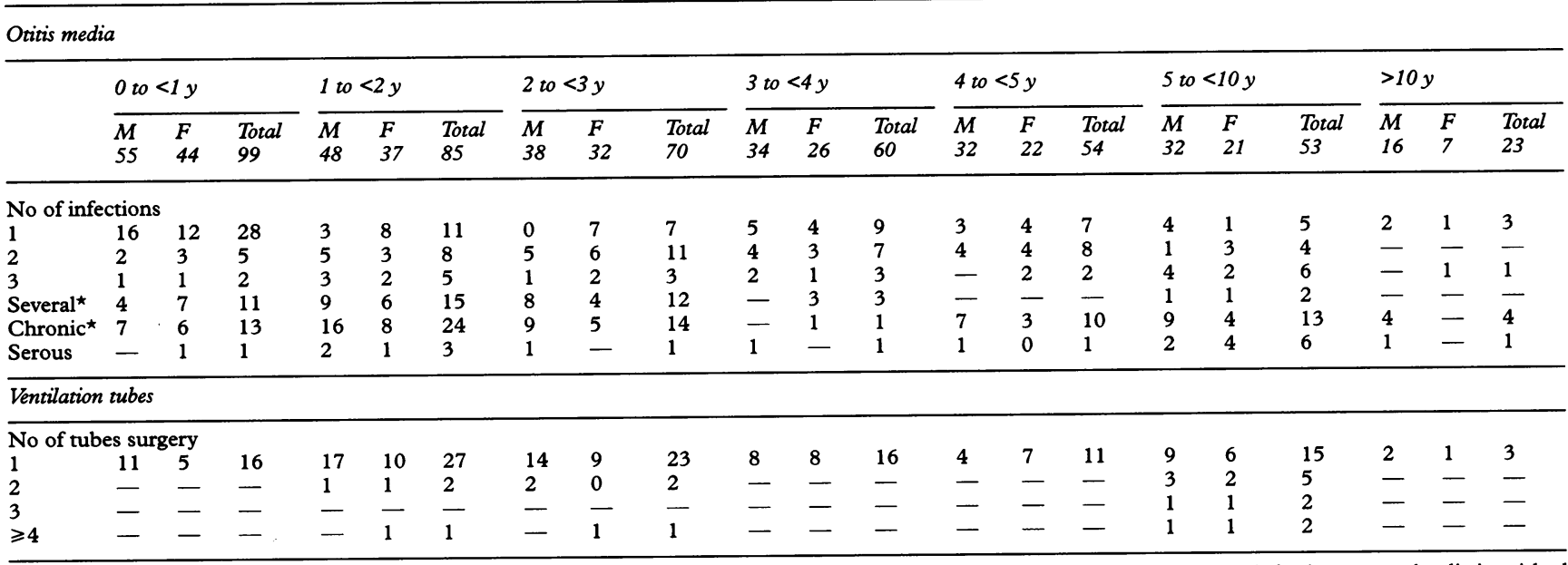

^Several defined as more than three separately diagnosed infections. Chronic defined as where the otitis appears continual and one infection cannot be distinguished from the next. 


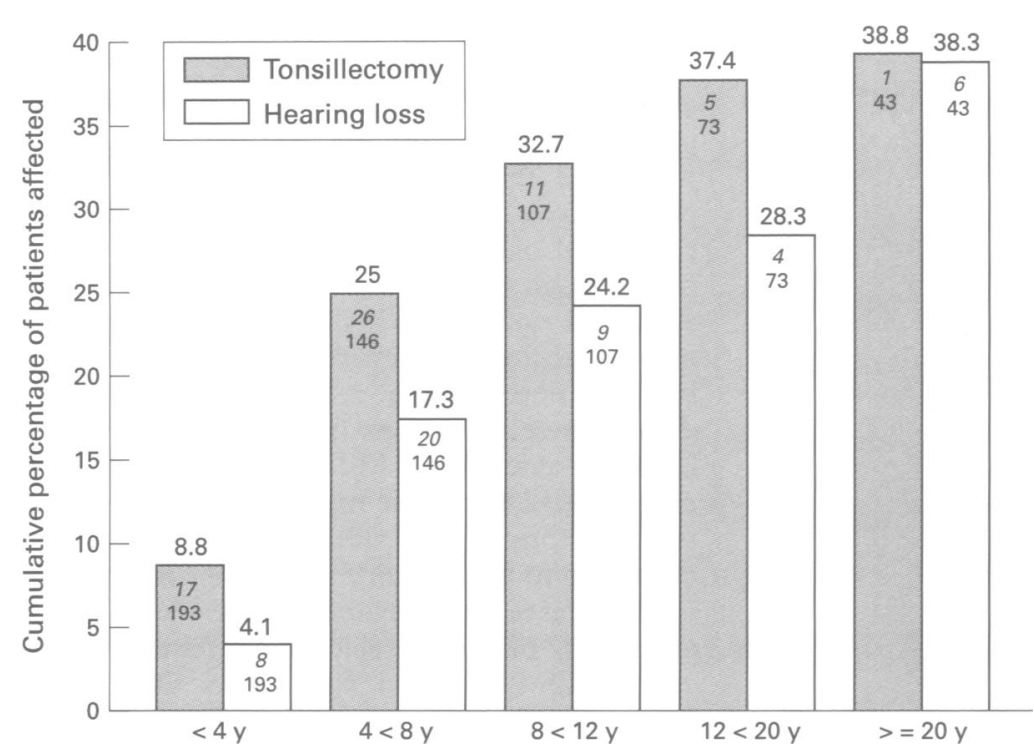

Figure 2 Cumulative rates of tonsillectomy and of "conductive hearing loss". Numbers within columns are the actual numbers affected over the numbers followed in that age category.

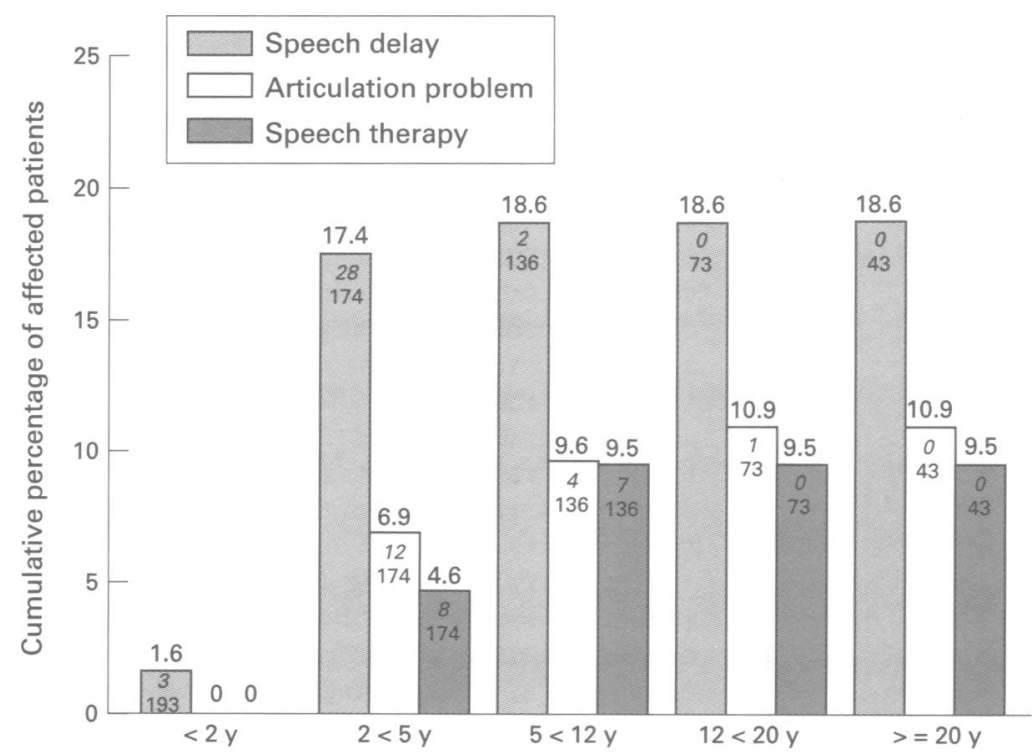

Figure 3 Cumulative rate of patients reported as having speech delay, articulation problems, or speech therapy. Numbers within columns are the actual numbers affected over the numbers followed in that age category.

follow up information is available falls with increasing age. In order to provide a cumulative incidence, the rate at which a complication occurred in a specific age group was applied as well to that part of the total previously unaffected patient sample not available at that follow up interval as if all had been available for study. For example, assume that 10 of 100 patients followed for a year have a certain complication, but only 50 patients in the 1 to 2 year group are available and that four of them have the problem. The rate of $4 / 50$ is then applied to the 40 "unavailable unaffected from year 1 " patients giving $7.2 / 100$ in year 2 , and a cumulative risk of $17.2 / 100$. Factors which may compromise the validity of this approach will include any temporal change in the occurrence of the complication and any bias in either the ascertainment, or lack of ascertainment, among those who continue to be followed versus those who are lost to follow up. Also, the number of adults available for follow up is lim- ited allowing a large margin of error in the estimates, especially for adult onset conditions. These factors need to be taken into account separately for each complication when considering the estimated rates.

Fig 2 suggests that almost $40 \%$ of patients will undergo tonsillectomy, the majority before the age of 8 years, but some in their teens or even adulthood. Conductive hearing loss appears to affect about $38 \%$ with about half of those detected before the age of 8 years.

Fig 3 provides data on the incidence of speech problems. Virtually all speech delay and articulation difficulties are recognised between the ages of 2 and 5 years and reach a rate of 19 and $11 \%$ respectively, with about $10 \%$ of subjects receiving speech therapy.

Fig 4 shows the rates at which patients were treated by orthodontics or were recorded as having a degree of malocclusion for which orthodontics were planned. The total of the two is also shown.

Fig 5 presents data on the frequency of intracranial shunts and whether they were carried out because of increasing head circumference or because of neurological signs attributed to hydrocephalus. About $11 \%$ of patients received shunts and these tended to be performed early in childhood.

Fig 6 shows that about $8 \%$ of children are reported as having apnoea by 1.5 years and that the rate continues to rise to about $16 \%$ by the teenage years. Foramen magnum and upper cervical surgery, which is often related to apnoea as a sign, is uncommon below 6 months and then continues to occur into adulthood with a cumulative rate of about $16 \%$. Neurological signs attributed to the cervical area are shown in fig 7.

Tibial bowing (fig 7) is generally not recorded until after the child begins to walk and while the incidence appears to continue to rise into adulthood it seems likely that this represents a degree of under-recording at younger ages and thus late recognition. Fig 8 shows that patients with significant tibial bowing are subject to tibial osteotomy beginning in mid childhood and that the cumulative rate rises to about $17 \%$ with the occasional procedure being carried out in adulthood.

The rates of leg and back pain and neurological symptoms of the arms and legs are summarised in figs 8 and 9. The latter was taken to include parasthesias, claudication, numbness, and limitation in walking.

Fig 10 presents the rate of spinal surgery and of patients diagnosed as having symptomatic spinal stenosis but who had not had surgery. The rate of formal recognition of spinal stenosis clearly lags behind the onset of symptoms attributable to spinal stenosis. Six patients reported loss of bladder function, and delay in treatment of symptomatic spinal stenosis may have consequences in terms of reversibility of symptoms.

\section{Discussion}

OTTTIS MEDIA, SPEECH, AND HEARING

Otitis media has been long recognised as a complication in achondroplasia, ${ }^{17}$ but there are 


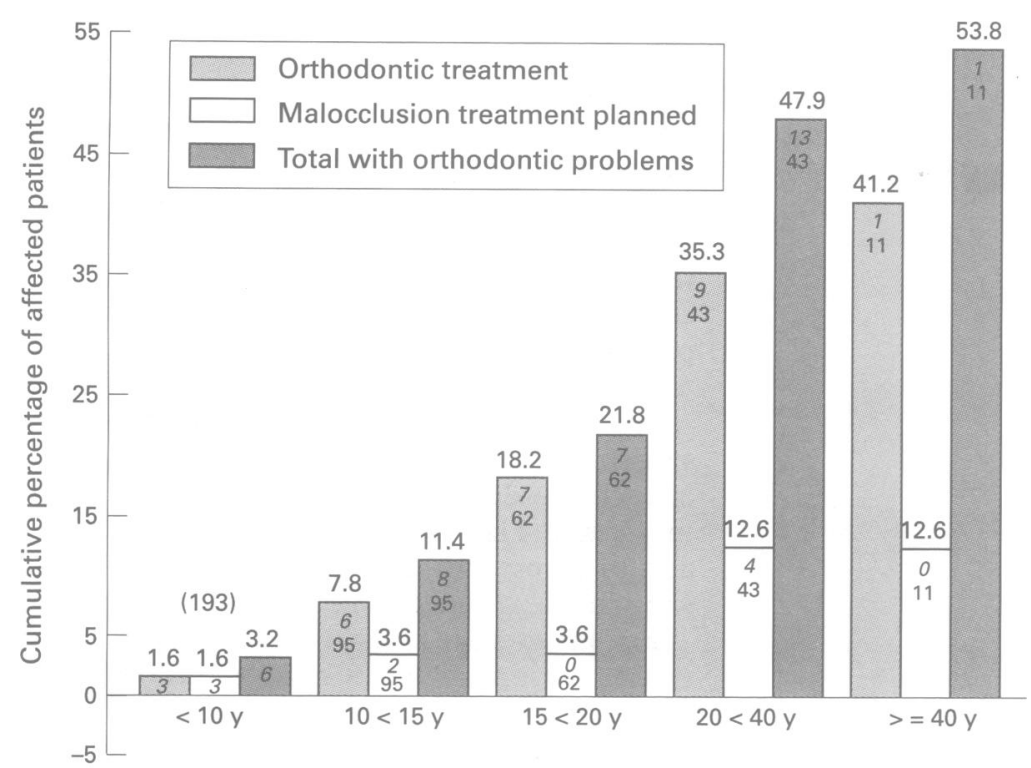

Figure 4 Cumulative rate of patients reported as having orthodontics, malocclusion needing orthodontics, and the total of the two. Numbers within columns are the actual numbers affected over the numbers followed in that age category.

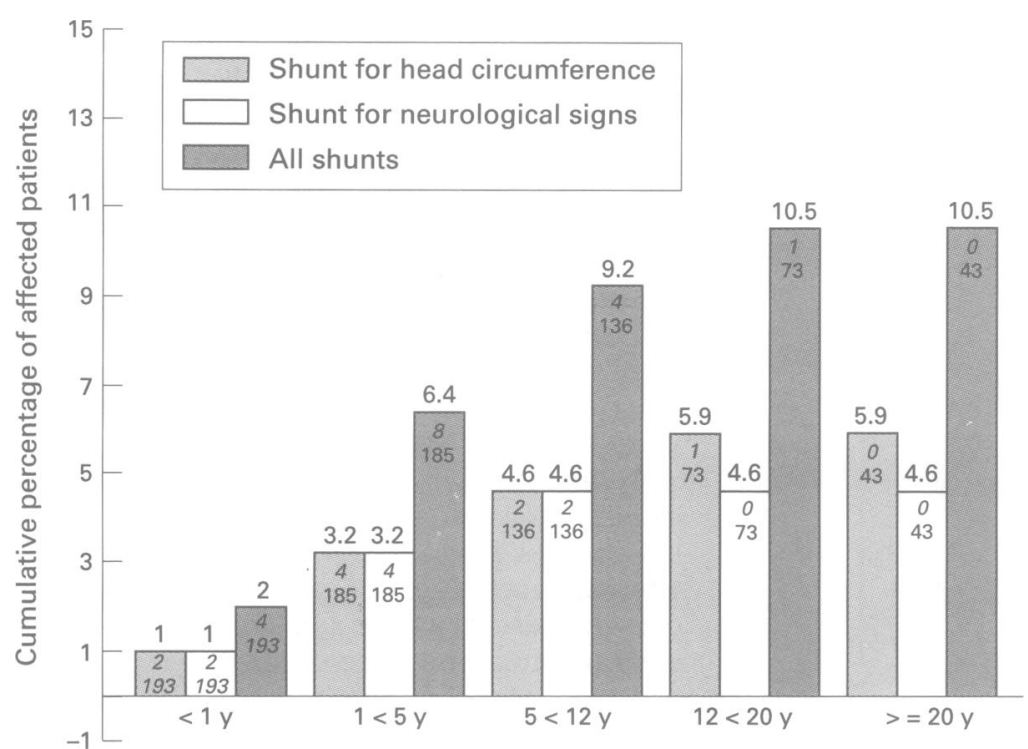

Figure 5 Cumulative rate of patients reported as having shunts for either increasing head size or for neurological signs and the total of the two. Numbers within columns are the actual numbers affected over the numbers followed in that age category.

few published data on the incidence of this problem. Hall ${ }^{15}$ apparently found that $75 \%$ of 150 patients in an unpublished series of patients with achondroplasia had suffered OM and that the rate fell to $11 \%$ over the age of 18 years. Berkowitz et $a l^{\prime}$ used the indirect measure of the insertion of ventilation tubes (VTs) to assess the impact of $O M$ and found that 33 of $61(54 \%)$ patients, 48 of whom were less than 5 years old, had had tubes inserted. Part of that series was from the Alfred I duPont Hospital for Children and thus some of those patients may be included in this report.

For purposes of this review, a record of otitis media in the interval since the last follow up visit was accepted as an event, although this clearly relies on the abilities of the primary care physician and does not allow any distinction between serous $O M$ and an acute infectious process. Sixty percent of patients had been diagnosed as having OM within their first year and only $10 \%$ remained disease free by the age of 2 years. The respective figures for VT were $16 \%$ and $58 \%$. The data suggest that about $7 \%$ of patients have not suffered OM by the age of 3 years and that about $5 \%$ of achondroplastic patients may not experience OM. However, the placement of VTs continues throughout childhood so that only $22 \%$ of those patients over 10 years had not had VTs. Of the $60 \%$ who were infected within the first year of life, more than half had more than one infection and 24/99 had either several infections or were considered to have chronic OM. Multiple infections and chronic OM had their maximal impact during the first three years, although chronic disease continues to be a factor for a significant minority of patients, even beyond the age of 10 . There appear to be more males than females with chronic OM. Table 3 also shows that 30/85 $(35 \%)$ of $1-2$ year olds and $26 / 70(37 \%)$ of $2-3$ year olds received at least one set of ventilation tubes and, while the rate per year fell with age, $47 \%$ of $5-10$ year olds received at least one set of tubes. There is no reason to expect that the patients in this series would be selected by the occurrence of middle ear disease and, while it is possible that the known propensity for $\mathrm{OM}$ in achondroplasia may have led to some overdiagnosis, the data suggest that the incidence of $O M$ and placements of VTs is even higher that previously thought. This high rate of OM has been considered secondary to the orientation and size of the eustachian tube ${ }^{19}$ as well as impaired nasal airflow and temporal bone abnormalities, ${ }^{7}$ although Pinelli et $a l^{20}$ considered the latter rare in achondroplasia. Stura $e t a l^{1}$ provided evidence for cochlear anomalies as the cause for the mild sensorineural impairment they observed in three cases.

The cause of hearing loss in patients with achondroplasia is most often conductive but the rate of sensorineural impairment may also be increased. ${ }^{182021}$ MacDonald $e t a l^{2}$ discussed 12 patients with conductive hearing loss and attributed seven to acute changes while five were considered to result from ossicular chain stiffness, either congenital or acquired owing to past chronic middle ear disease. Malformations of the ossicular chain have been reported from single patients in two previous series. ${ }^{72}$ While these previous studies have the advantage of more complete audiological evaluations, they are limited by relatively small numbers (18-28 patients), a paucity of paediatric data, ${ }^{18}$ or selected referral to an ENT department. ${ }^{22}$ The cumulative figures for conductive hearing loss in the present study show that by adulthood about $38 \%$ of patients will have had this diagnosis. Not included are an additional two patients recorded as having sensorineural impairment. Audiograms were not available and it is very possible that a greater proportion of the hearing loss was sensorineural. While only $4 \%$ are diagnosed before the age of 4 years, the time of most active OM, the jump to $17 \%$ by the age of 8 is to be expected because of investigation of speech difficulties (see below) and detection of school associated problems. The data do not allow any assessment of the permanency of the loss (much is likely to be temporary) or the underlying 


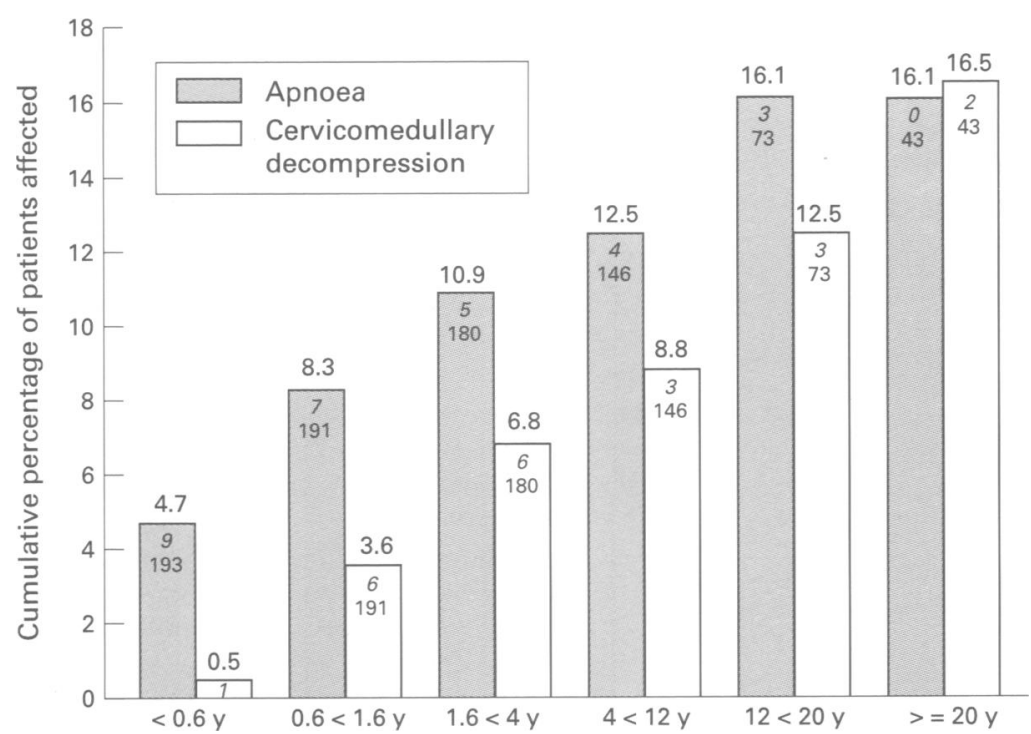

Figure 6 Cumulative rates of clinical apnoea and of cervicomedullary decompression surgery. Numbers within columns are the actual numbers affected over the numbers followed in that age category.

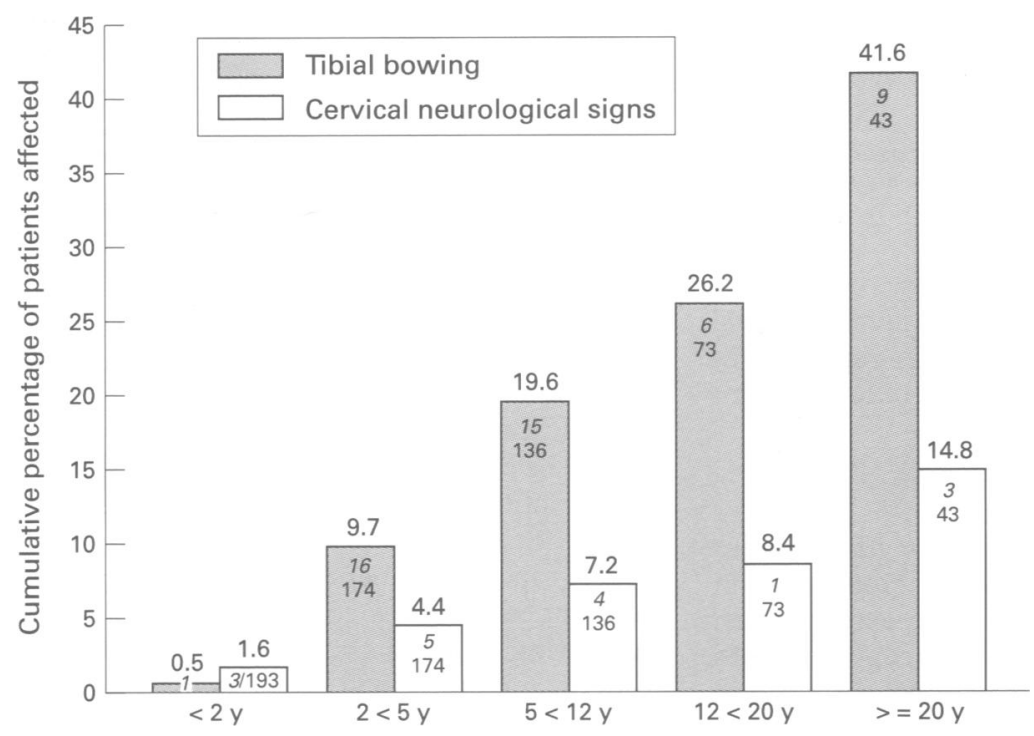

Figure 7 Cumulative rates of tibial bowing and neck neurological signs. Numbers within columns are the actual numbers affected over the numbers followed in that age category.

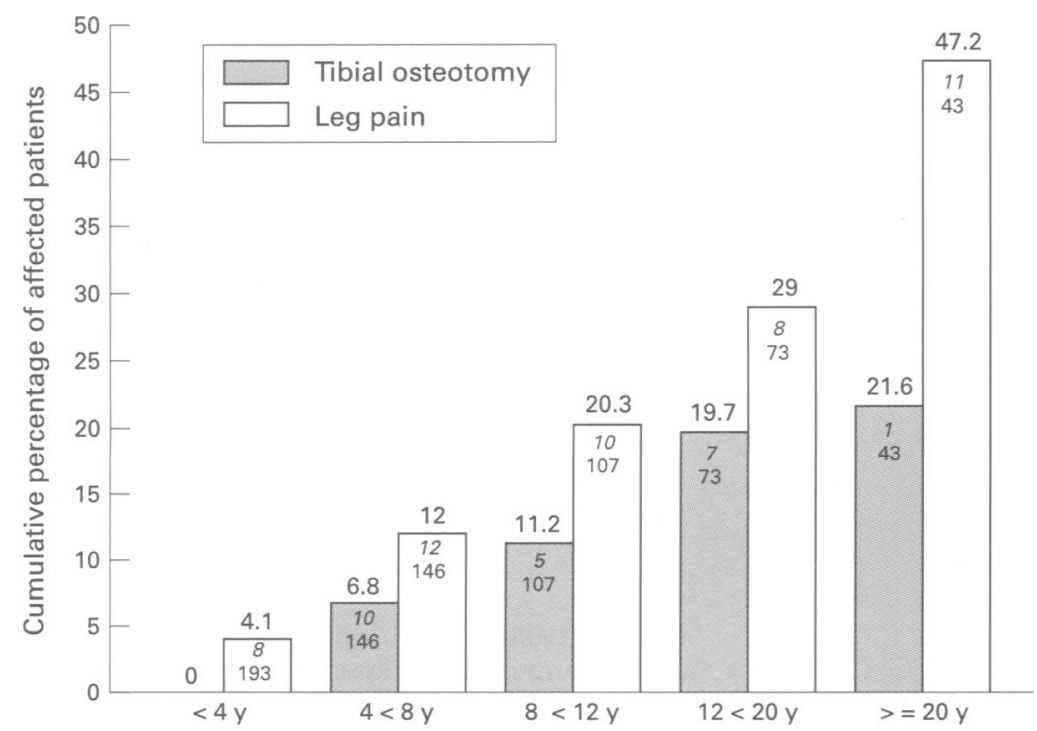

Figure 8 Cumulative rate of patients complaining of leg pain and of those having tibial osteotomy. Numbers within columns are the actual numbers affected over the numbers followed in that age category. aetiology. The continued placement of VTs and of tonsillectomy into late childhood suggests that in many cases it was considered associated with middle ear disease. Even transient hearing impairment may have an important impact on the acquisition of language and learning.

SPEECH AND LANGUAGE

Delay in the acquisition of speech is a recognised complication in achondroplasia. The American Academy of Pediatrics (AAP) guidelines ${ }^{16}$ recommend speech evaluation by 2 years of age and it is part of their anticipatory care. Emphasis is placed upon ruling out conductive hearing loss as a cause. Hall ${ }^{15}$ includes tongue thrust, resulting from the abnormal maxillomandibular relationship, as a component of this delay, and presumably also for articulation problems. There do not appear to be published data on the overall significance of these problems. From this review it appears that about $20 \%$ of children with achondroplasia are delayed in acquiring speech and that, as expected, the vast majority are noted between the ages of 2 and 5 years. Recognition of articulation problems which were reported in $11 \%$ of patients, some of whom also experienced speech delay, followed the same age pattern. It would appear that less than half of the children who experience these problems are receiving formal therapy. The data do not allow the cause of the speech delay or articulation problems to be identified. While several children were ultimately considered as slow learners (9) or mentally retarded (4), those children were a minority of those with delayed language acquisition. While the nature of these data do not allow for statistical evaluation of the possible association of speech delay and articulation problems with hearing loss or dental malocclusion, examination of our data did not show any evidence that hearing loss or malocclusion was more common in the children with speech problems than in those without such difficulties. While craniofacial anomalies and tongue thrust might be considered more important in the articulation than in the acquisition of speech, we have posited that disproportion of the tongue may be resposible for the delay in speech seen in some children with BeckwithWiedemann syndrome. ${ }^{23}$ It is to be hoped that speech therapy will become more readily available in the current era.

\section{DENTAL}

The dental concern in achondroplasia is for a class III malocclusion because of the disproportionate growth of the cranial base which leads to severe maxillary retrusion and a decreased maxillary vertical height. ${ }^{24}$ Furthermore, the teeth may be crowded and a narrow upper jaw may lead to a crossbite (D E Engst, personal communication). It is recommended that all children with achondroplasia be evaluated for possible orthodontic needs by the age of 5 or 6 years $^{16}$ (D E Engst, personal communication). Only $3 \%$ of the children in this review were recorded as having a significant orthodontic need before the age of 10 years and in many cases treatment did not occur until the late teens or early adulthood. Ultimately, over $50 \%$ of 


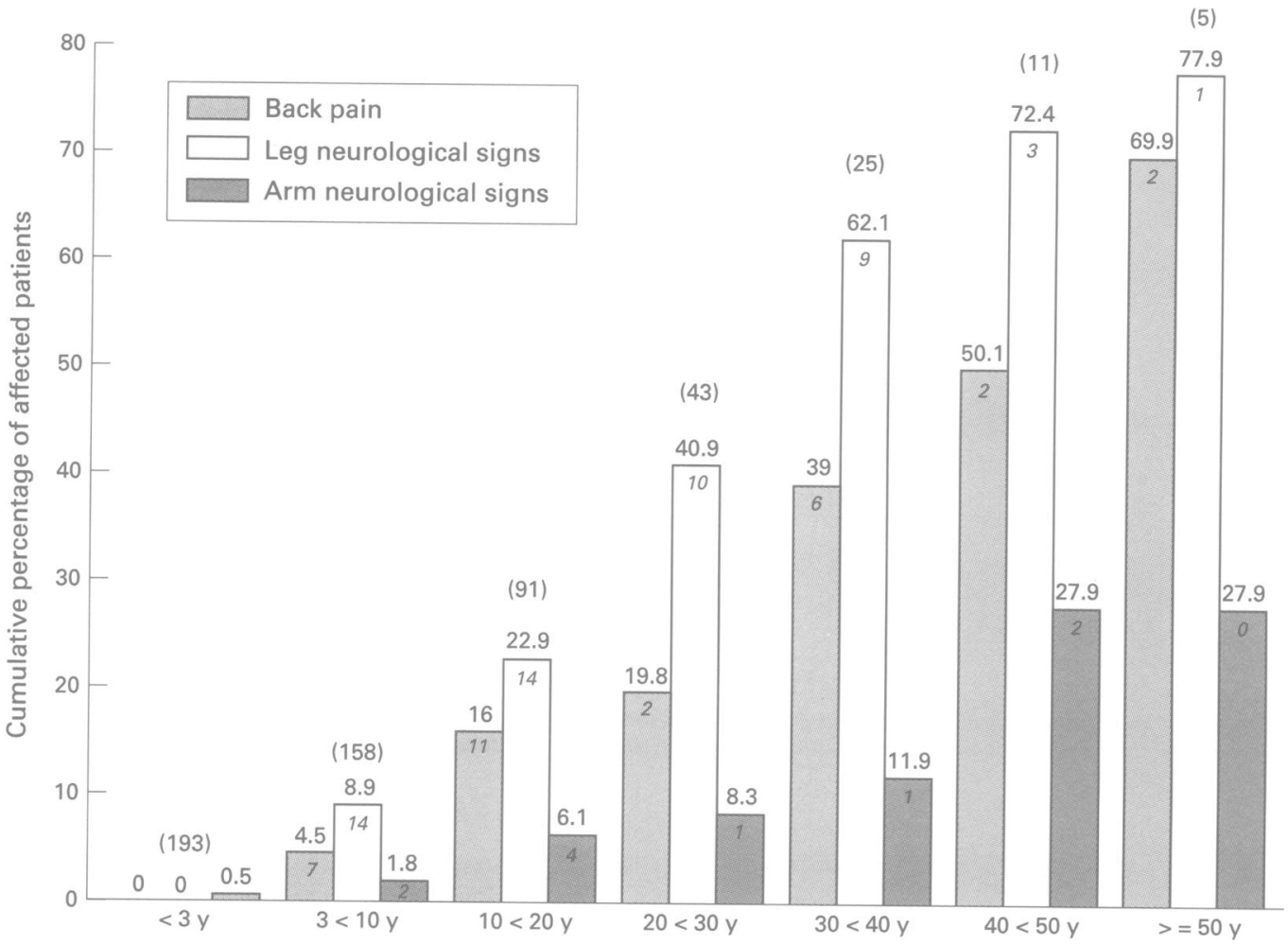

Figure 9 Cumulative rate of patients reported as having back pain, neurological signs in the legs, and neurological signs in the arms. Numbers within columns are the actual numbers affected while those in brackets above the columns are the numbers followed in that age category.

patients were noted to have an orthodontic problem and $40 \%$ received treatment. Dental problems are significantly under-reported in medical charts and these figures may represent an underestimate of the problem.

\section{VENTRICULAR SHUNTING}

Hurko et $a l^{5}$ have pointed out that earlier enthusiasm for ventricular shunting in achondroplasia has, to a large extent, been replaced by the view that hydrocephalus does not occur to a degree that requires shunting in most cases of achondroplasia. While aqueductal stenosis has been reported in achondroplasia, ${ }^{26}$ it is unusual and can be distinguished from the common ventriculo-

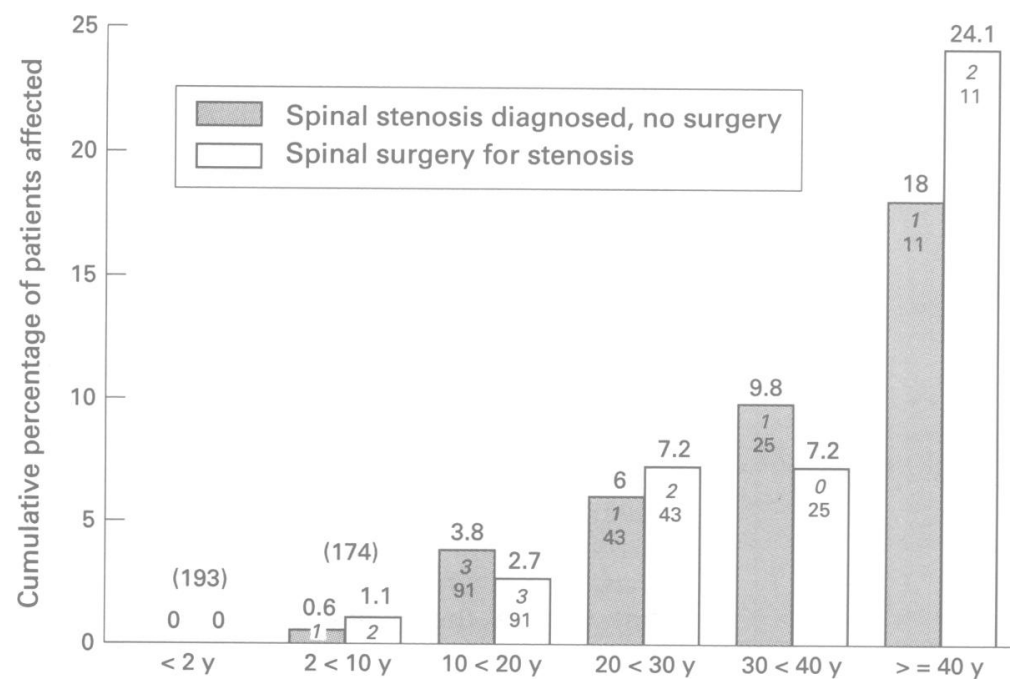

Figure 10 Cumulative rates of symptomatic spinal stenosis and of spinal surgery. Numbers within columns are the actual numbers affected over the numbers followed in that age category. megaly seen in achondroplasia by the lack of prominent sulci and frontal subarachnoid space characteristic of achondroplasia. When hydrocephalus does occur, it is almost always communicating and may relate to venous outflow at the cranial foramen or at the cervicothoracic junction. ${ }^{9}$ The diagnosis of hydrocephalus in achondroplasia is not trivial given the background macrocrania and ventriculomegaly, but there appears to be a consensus ${ }^{525}$ that careful monitoring of head circumference and development, including gait, against the published norms for achondroplasia will distinguish patients with symptomatic hydrocephalus. Hurko et $a l^{25}$ go further and suggest that surgery should be reserved for those patients whose increased intracranial pressure has been shown by either extra- or intracranial monitoring. It is not known whether any of the patients in this series had such monitoring. The stated criteria for surgery were evenly split between the head circumference crossing centiles and neurological signs attributed to hydrocephalus (fig 5). About $11 \%$ of patients underwent shunting with the rate per year remaining quite similar throughout childhood. Only one teenager and no adult was shunted. It was not possible to determine from the data whether the patients benefited from the shunting or whether there were children who were overlooked when shunting would have been appropriate.

CERVICOMEDULLARY COMPRESSION

Narrowness and related anatomical variation of the foramen magnum and upper cervical spine in achondroplasia have potential to cause significant complications. ${ }^{452527}$ It has been shown that the average adult with 
achondroplasia has a foramen magnum that is equivalent to that of a newborn in transverse and that of a 2 year old in sagittal diameter. ${ }^{5}$ This reduced area is further compromised by anterior placement of the foramen which results in superior displacement of the brainstem, causing the upper cervical cord to traverse the foramen, and concurrent hyperextension of the brainstem, even at a neutral head position. ${ }^{25}$ Cervicomedullary compression is considered to account for a significant proportion of the early excess mortality, ${ }^{28}$ apnoea, ${ }^{427}$ and progressive paraparesis ${ }^{52}$ in achondroplasia. Hurko et $a l^{25}$ raised the provocative notion that it might play a role in the virtual universal early hypotonia and motor delay seen in affected infants.

There are not universally agreed upon criteria for operative intervention in the face of assumed symptomatology resulting from cervicomedullary compression. Rates of intervention as high as 34 and $42 \%$ have been reported from patient series largely selected because of symptomatology. ${ }^{49}$ Pauli et al ${ }^{28}$ performed surgery on five of 53 prospective cases and argued that measurements of the foramen magnum, central hypopnoea, and hyperreflexia/ clonus were the best predictors of the need for surgery. Rimoin ${ }^{30}$ countered that the arguments were tautological and reported that $9 / 200$ cases in his group had had surgery (including some whose surgery was performed before referral) and with a series mortality of only $1 / 200$. He predicted, based on unpublished experience, that lack of anterior and posterior CSF flow and the presence of intracord lesions would prove to be the best predictors of the need for surgery. In fact the surgical exposure rates between the two groups were not statistically different. Short of a large randomised multicentre trial it is difficult to see how intervention will be optimised. The patients in this study have been ascertained through departments of genetics and are thus unlikely to be significantly selected for symptomatology. The rate of surgical intervention by the age of 4 years $(6.8 \%$, fig 6$)$ is intermediate between that of Rimoin, ${ }^{30}$ who did not provide age data, and that of Pauli $e t a{ }^{28}$ whose patients were of comparable age. However, it is important to emphasise that the apparent need for intervention, primarily because of progressive neurological symptoms, may continue into adulthood $^{31}$ and that ultimately about $17 \%$ of patients may undergo this surgery (fig 6).

The rates of apnoea, neurological impairment of the arms, or neurological signs attributed to the cervical region are summarised in figs 6,9 , and 7, respectively. For two of the 21 patients who underwent cervicomedullary decompression, the indication was not recorded. Of the remainder, nine were recorded as having cervical signs, four apnoea, one with both, three with neurological impairment of the arms and legs, and two with impairment limited to the legs. The latter two groups tended to be older.

TIBIAL BOWING

Tibial bowing is considered to be a hallmark of achondroplasia and is one of three anomalies of the structure of the knee, which also include tibial genu recurvatum and lateral torsion. ${ }^{32}$ It is believed to be secondary to the relative overgrowth of the fibula as compared to the tibia, and it is considered clinically significant when when the ankle +/- knee fall outside a plumbline dropped from the hip. Milder cases are common and the rate will to some extent depend upon the definition used. For this series, a distance $\geqslant 5 \mathrm{~cm}$ between the knees, with the legs straight and the ankles apposed, was used and the rate in fig 7 shows the expected jump at the time of onset of walking, but with continued significant numbers of cases diagnosed into adulthood. There appear to be few published comparative data. Kopits ${ }^{8}$ reported that $50 \%$ of patients had bowing but that in only half was a joint outside the hip plumbline. No ages were given. Later he stated that parents note a varus deformity in $40 \%$ of the children as they begin to stand and that $93 \%$ of adults are affected. ${ }^{32}$ The adults reported as unaffected were seen at the time of this survey and clearly a significant proportion did not have tibial bowing as defined. The age groupings shown are the ages at first recording of the bowing and should not be construed to represent the age of onset. Kopits ${ }^{8}$ found that only $10 \%$ of his patients offered surgery $(2.5 \%)$ of the total group accepted. From this review it is estimated that about $22 \%$ of patients had osteotomies, with most being carried out in childhood but a significant number being performed on teenagers and young adults (fig 8).

\section{SPINAL STENOSIS}

The average area of $\mathrm{L} 1$ is said to be reduced by $39 \%$ and of L5 by $27 \%$ in achondroplasia, ${ }^{33}$ and yet the average age of onset of symptoms is said to be 38 years. ${ }^{34}$ A number of factors associated with normal or specific achondroplastic ageing are thus considered to play a role in the onset of symptoms. These include disc protrusion, spondyloarthritic spurs, a kyphotic wedge, excess lumbar lordosis (perhaps excacerbated by excess weight), a bulging annulus fibrosis, and vertebral malalignment/ instability. ${ }^{5} 1035$ Leg (fig 8) and lower back (fig 9) pain (including the buttock) may be early presenting signs of spinal stenosis. The leg pain in early childhood is more likely a consequence of local changes at the knee, secondary to fibular overgrowth. ${ }^{32}$ Kopits ${ }^{32}$ claims that $70 \%$ of children with achondroplasia aged 4 to 10 years have leg pain. This is far higher than the rate recorded here and may represent some selective bias to a surgical practice. By the age of 12 years, only $20 \%$ of children were recorded as having leg pain but this had risen to almost $50 \%$ by adulthood with most of the increase probably the result of symptomatic spinal stenosis. Less than $10 \%$ of 10 year olds had neurological signs related to their legs but this rises to $20 \%$ by the end of the teens and to $80 \%$ by the 50 s. Back pain showed a fairly parallel rate of onset (fig 9). The numbers in the adult intervals are small and there could be some selection bias in seeking follow up.

Comparison with published series is highly age dependent. Hall ${ }^{15}$ quotes a 1974 LPA survey where $20-30 \%$ of patients reported symptoms of 
stenosis and $10 \%$ were considered to require surgery. Bethem et $a l^{10}$ reported that $7 / 30$ of their patients with achondroplasia had claudication or flaccid paralysis because of spinal stenosis. Nelson $^{36}$ reported three series of patients. In a historic group, 38/51 patients below the age of 15 were asymptomatic, two had back pain, and 11 a significant kyphosis. Three of seven between 15 and 29 years had neurological signs and one had back pain. All 12 patients over the age of 30 had neurological signs. The second survey comprised questionnaire replies about back pain from 67 members of the Association for Research into Restricted Growth (ARRG). Nineteen of 27 males aged 12 to 65 years, and 31 of 40 females aged 12 to 75 years had back pain. In a personal series of 37 patients (four with hypochondroplasia), seven had back pain alone and 10 had symptomatic spinal stenosis.

\section{Conclusion}

This study showed an encouraging trend to earlier diagnosis of achondroplasia and provided data on the rates of some of the more common health concerns. Middle ear disease, with its attendant risk of hearing loss, was even more frequent than previously reported, and while a significant minority of patients experienced delay in the acquisition of speech or articulation difficulties or both, only a minority of those received speech therapy. The identification and treatment of orthodontic problems was significantly delayed and the need probably under-recognised. The rate of early cervicomedullary decompression was comparable to reported series, but it appears that an equivalent proportion of patients require such intervention beyond childhood.

The patients reported in this series were cared for at a time before the promulgation of guidelines for care, such as those of the American Academy of Pediatrics, ${ }^{16}$ and before the trend to mutidisciplinary clinics. However, most such efforts have a paediatric focus. Our data have shown that a significant number of patients have neurological complaints by their teens and that this becomes the majority in adulthood. During these years, care is often fragmented with little emphasis on prevention and early intervention. During the study many adults were interviewed who had major physical limitations and pain which seriously affected their quality of life. It is a clear challenge for the future to improve the care provided to these people.

The people who helped with this study, both professional and the patients and their families, are more thoroughly acknowledged in Hunter. ${ }^{6}$ We again wish to thank them all, for without their selfless help this study would not have been possible. The support of the Children's Hospital of Eastern Ontario for D Hunter's sabbatical leave is again acknowledged.

1 Oberklaid F, Danks DM, Jensen F, Stace L, Rosshandler S Achondroplasia and hypochondroplasia. Comments on Achondroplasia and hypochondroplasia. Comments on frequency, mutation rate, and radiologica

2 Hecht JT, Francomano CA, Horton WA, Annegers JF. Mortality in achondroplasia. Am $₹$ Hum Genet 1987;41:454-64. 3 Pauli RM, Scott CI, Wassman ER Jr, et al. Apnea and sudden unexplained death in infants with achondroplasia. $f$ Pediatr 1984;104:342-8.

4 Reid CS, Pyeritz RE, Kopits SE, et al. Cervicomedullary compression in young patients with achondroplasia: value of comprehensive neurologic and respiratory evaluation. $f$ Pediatr 1987;110:522-30.

5 Hecht JC, Butler IJ. Neurologic morbidity associated with achondroplasia. $\mathcal{F}$ Child Neurol 1990;5:84-97.
6 Hunter AGW. Craniofacial anthropometrics in several types of chondrodysplasia. Am $\mathcal{F}$ Med Genet 1996;65:5-12.

7 Berkowitz RG, Grundfast KM, Scott C, Saal H, Stern Hrosenbaum $K$. Middle ear disease in childhood achondroplasia. Ear Nose Throat $\mathcal{F}$ 1991;70:305-8.

8 Kopits SE. Orthopedic complications of dwarfism. Clin Orthop Rel Res 1976;114:153-79.

9 Steinbok P, Hall J, Flodmark O. Hydrocephalus in achondroplasia: the possible role of intracranial venous hypertension. $\mathcal{F}$ Neurosurgery 1989;71:42-8.

10 Bethem D, Winter RB, Lutter L, et al. Spinal disorders of dwarfism. F Bone foint Surg (Am) 1981;63:1412-25.

11 Hecht JT, Hood OJ, Schwartz RJ, Hennessey JC, Bernhard BA, Horton WA. Obesity in achondroplasia. Am $\mathcal{F}$ Med Genet 1988:31:597-602

12 Scott CI Jr. Medical and social adaptation in dwarfing conditions. Birth Defects 1977;XIII(3C):29-43

13 Stace L, Danks DM. A social study of dwarfing conditions II. The experience of children with bone dysplasias and of their parents. Aust Paediatr J 1981;17:172-6.

14 Nicoletti B, Kopits SE, Ascani E, McKusick VA, eds Human achondroplasia. A multidisciplinary approach. New York: Plenum Press, 1988;48:3-9.

15 Hall J. The natural history of achondroplasia. In: Nicoletti B, Kopits SE, Ascani E, McKusick VA, eds. Human achondroplasia. A multidisciplinary approach. New York: Plenum Press, 1988;48:3-9.

16 American Academy of Pediatrics. Committee on Genetics. Health supervision for children with achondroplasia. Pediatrics 1995;95:443-51.

17 Cohen MM. Dysmorphic syndromes with craniofacial manifestations. In: Stewart RE, Prescott G, eds. Oral facial genetics. St Louis: Mosby 1976:523-5.

18 Glass L, Shapiro I, Hodge SE, Bergstrom L, Rimoin DL Audiological findings of patients with achondroplasia. Int $\mathcal{F}$ Pediatr Otorhinolarygol 1981;3:129-35.

19 Crawford DB, Ensor RE, Dorst JP. The chondrocranium in achondroplasia. In: Bosma JF, ed. Development of the basicranium. Bethesda: US Department of Health Education and Welfare Publication No NIH 76-989, 1976:301-8.

20 Pinelli V, Masi R, Partipilo P, Pierro V, Tieri L. Otologic impairments in achondroplasia: a nosologic assessment. In Nicoletti B, Kopits SE, Ascani E, McKusick VA, eds. Human achondroplasia. A multidisciplinary approach. New Human achondroplasia. A multidis

21 Stura M, Boero S, Origo C, Tarantino V. Evaluation of hearing in achondroplastic patients. In: Nicoletti B, Kopits SE Ascani E, McKusick VA, eds. Human achondroplasia. $A$ multidisciplinary approach. New York: Plenum Press 1988 183-4

22 MacDonald JM, Seipp WS, Gordon EM, Heroy J. Audiologic findings in achondroplasia. In: Nicoletti $\mathrm{B}$, Kopits SE, Ascani E, McKusick VA, eds. Human achondroplasia. A multidisciplinary approach. New York: Plenum Press, 1988:143-7.

23 Hunter AGW, Allanson JE. Follow-up study of patients with Wiedemann-Beckwith syndrome with emphasis on the change in facial appearance over time. Am $\Im$ Med Genet change in facial

24 Dunbar JP, Goldin B, Subtelny JD. Correction of class I crowding in an achondroplastic patient. Am $\mathcal{f}$ Orthod Dencrowding in an achondroplas

25 Hurko O, Pyeritz R, Uematsu S. Neurological considerations in achondroplasia. In: Nicoletti B, Kopits SE, Ascan E, McKusick VA, eds Human achondroplasia. A multidiscipli nary approach. New York: Plenum Press, 1988:153-62.

26 Cohen ME, Rosenthal AD, Matson DD. Neurological abnormalities in achondroplastic children. $\mathcal{F}$ Pediatr 1967; 71:367-76

27 Aryanpur J, Hurko O, Francomano C, Wang H, Carson B. Craniocervical decompression for cervicomedullary compression in pediatric patients with achondroplasia. 7 Neurosurg 1990;73:375-82.

28 Pauli RM, Horton VK, Glinski LP, Reiser CA. Prospective assessment of risks for cervicomedullary junction compresassessment of risks for cervicomedullary junction compres-
sion in infants with achondroplasia. Am $\mathcal{F}$ Hum Genet 1995; 56:732-44

29 Francomano CA, Carson B, Seidler A, et al. Morbidity and mortality in achondroplasia: efficacy of prospective evaluation and surgical intervention. Am $\mathcal{F}$ Hum Genet Supp 1993;53:A112.

30 Rimoin DL. Cervicomedullary junction compression in infants with achondroplasia: when to perform neurosurgical decompression. Am f Hum Genet 1995;56:824-6.

31 Morgan DF, Young RF. Spinal neurological complications of achondroplasia: results of surgical treatment. Neurosurgery 1980;52:111-13.

32 Kopits SE. Orthopedic aspects of achondroplasia in children. In: Nicoletti B, Kopits SE, Ascani E, McKusick VA, eds. Human achondroplasia. A multidisciplinary approach. New York: Plenum Press 1988:189-97.

33 Lutter LD, Longstein JE, Winter RB, Langer LO. Anatomy of the achondroplastic lumbar canal. Clin Orthop 1977;126 of the ach

34 Lutter LD, Langer LO. Neurological symptoms in achondroplastic dwarfs-surgical treatment. $\mathcal{f}$ Bone foint Surg droplastic dwarfs-surg.
$(\mathrm{Am})$ 1977;59:340-4

35 Fortuna A, Ferrante L, Acqui M, Santoro A, Mastronardi L. Narrowing of thoraco-lumbar canal in achondroplasia. $\tilde{f}$ Neurol Sci 1989;33:185-96.

36 Nelson MA. Kyphosis and lumber stenosis in achondroplasia. In: Nicoletti B, Kopits SE, Ascani E, McKusick VA eds. Human achondroplasia. $A$ multidisciplinary approach. New York: Plenum Press, 1988:305-11. 